\title{
PENGARUH HARGA, KUALITAS PELAYANAN \\ DAN KUALITAS PRODUK TERHADAP MINAT PEMBELIAN ULANG \\ DAN KEPUASAN PELANGGAN ONLINE SHOPPING \\ PADA REMAJA DI SITUBONDO
}

Submitted Date :

14 Nopember 2019

Accepted Date :

28 Nopember 2019
Rini Kartika Sari

Universitas Abdurachman Saleh Situbondo

rinikartika1903@gmail.com

Nanik Hariyana

Universitas Abdurachman Saleh Situbondo

hariyana.nanik@yahoo.com

Suggested Citation:

Kim, Changsu,. Galliers, Robert D., Ryood, Joo-Han,. Shinc, Namchul and Kime, Jongheon. 2012. Factors Influencing Internet Shopping Value and Customer Repurchase Intention. Electronic Commerce Research and Applications. Vol. 11 (4): 374-387.

\section{Abstract:}

The purpose of this research is to analyze the effect of price, service quality and product quality on repurchase interest and online shopping customer satisfaction. This research was conducted on adolescents in Situbondo who subscribed to online shopping. The analysis technique used in this research is Structural Equation Modeling (SEM) Analysis. The results showed that price, service quality and product quality affect the interest in repurchase, as well as price, service quality and product quality affect customer satisfaction, and repurchase interest affect customer satisfaction online shopping.

Keyword : Interest in repeat purchases, customer satisfaction, price, service quality, product quality.

\section{Abstrak:}

Tujuan dilakukan penelitian ini adalah untuk menganalisis pengaruh harga, kualitas pelayanan dan kualitas produk terhadap minat pembelian ulang dan kepuasan pelanggan online shopping. Penelitian ini dilakukan pada remaja di Situbondo yang berlangganan online shopping. Teknik analisis yang digunakan dalam penelitian adalah Analisis Structural Equation Modelling (SEM). Hasil penelitian menunjukan bahwa harga, kualitas pelayanan dan kualitas produk berpengaruh terhadap minat pembelian ulang, serta harga, kualitas pelayanan dan kualitas produk berpengaruh terhadap kepuasan pelanggan, dan minat pembelian ulang berpengaruh terhadap kepuasan pelanggan online shopping.

Kata Kunci: Minat pembelian ulang, kepuasan pelanggan, harga, kualitas pelayanan, kualitas produk JEL Classification : M21, M31 


\section{Pendahuluan}

Kegiatan belanja online merupakan salah satu cara baru dalam berbelanja yang sedang trend digunakan dalam transaksi jual beli, terutama pada kalangan remaja karena Masa remaja adalah masa peralihan dimana perubahan secara fisik dan psikologis dari masa kanak-kanak ke masa dewasa (Hurlock, 2003:206). Perubahan psikologis yang terjadi pada remaja meliputi intelektual, kehidupan emosi, dan kehidupan sosial. Muagman (1980) dalam Sarwono (2006:280) mendefinisikan remaja berdasarkan definisi konseptual World Health Organization (WHO) yang mendefinisikan remaja berdasarkan 3 (tiga) kriteria, yaitu: biologis, psikologis, dan sosial ekonomi. Kegitan remaja yang sering dijumpai pada perkembangan sekarang, salah satunya adalah belanja online.

Toko online yang merupakan bentuk jual beli melalui alat komunikasi elektronik atau jejaring sosial, di mana pembeli tidak perlu susah payah datang ke toko untuk melihat dan membeli apa yang mereka cari karena dengan adanya belanja online mereka hanya tinggal melihat barang yang diinginkan di internet kemudian memesan barang sesuai pilihan dan mentransfer uangnya, lalu barang dikirim oleh toko online dan sampai kerumah (Meskaran et al. 2013). Toko online adalah bentuk perubahan yang disajikan oleh internet dari segi inovasi dalam berbelanja. Pada setiap kesempatan toko online menjadi perbincangan oleh sebagian kalangan masyarakat (Nurtjahjanti, 2012). Toko online memberikan berbagai kemudahan dalam proses transaksinya.

Online shop yang kita ketahui di internet banyak terdapat menjual berbagai macam kebutuhan manusia seperti tas, sepatu, pakaian, barang elektronik, perabotan rumah tangga, dan masih banyak lainnya. Trend online shop saat ini sering kita jumpai dengan mudah karena adanya peluang pasar di era digital dan perkembangan teknologi yang semakin canggih. Area bisnis telah memengaruhi pemakaian komputer (Sudaryanto, 2011). Sehingga Gaya hidup masyarakat saat ini ikut berubah karena pengaruh dari perkembangan teknologi tersebut, salah satu yang paling mencolok dari perkembangan teknologi tersebut adalah penggunaan gadget dan kecenderungan beraktivitas di dunia maya seperti berbelanja secara online atau lebih sering disebut dengan belanja online (Setiowati dan Jasly, 2012).

Bisnis online semakin terbuka untuk menjalankan peluang bagi pelaku bisnis di Indonesia. Terjadi pemutusan rantai perantara yang substansial dari pedagang grosir ke pengecer yang disebabkan oleh perdagangan secara elektronik. Bisa dikatakan semua produk saat ini tersedia tanpa harus mengunjungi toko (Kotler, 2007: 5). Berdasarkan pernyataan Kotler tersebut dapat kita lihat bahwa dengan internet (elektronik), kita dapat menemukan semua produk di internet tanpa harus mendatangi toko bahkan hingga pada makanan, pakaian dan peralatan rumah tangga sekarang juga dapat kita temukan di internet. Hal ini terjadi, karena tuntutan hidup manusia yang serba cepat, khususnya masyarakat di kota-kota besar yang memiliki berbagai kebutuhan dengan keterbatasan waktu berbelanja, online shopping telah menjadi salah satu alternatif. Strategi ini digemari oleh perusahaan-perusahaan besar, maupun yang tergolong usaha kecil dengan modal yang minim.

Penggunaan internet semakin populer dikacamata para generasi muda tak terkecuali remaja yang ada di Situbondo. Remaja dekat dan erat hubungannya dengan perkembangan teknologi, ilmu pengetahuan dan infomasi (Praja dan Damayantie, 2010). Berbagai kesempatan dilingkungan sosial remaja yang ada di Situbondo sering kali memperbincangkan mengenai online shop. Online shop menjadi topik perbincangan untuk menjalin komunikasi antara remaja satu dengan yang lainnya. Hal ini menunjukkan bahwa remaja yang ada di Situbondo juga dekat dengan internet dan tak bisa dipungkiri para remaja pun termasuk ke golongan konsumen yang pernah membeli secara online melalui media social atau fasilitas online yang sering digunakan remaja di Indonesia.

\section{Metode Penelitian}

Penelitian ini menggunakan data primer, yaitu diperoleh melalui penyebaran daftar pernyataan (kuesioner) berkaitan dengan variabel yang diteliti, yang diberikan kepada remaja di Situbondo yang berjumlah 125 responden. Alat analisis data yang digunakan di dalam penelitian ini adalah Uji Instrumen Data, Uji Normalitas Data, dan analisis Structural Equation Modelling (SEM). 


\section{Hasil Penelitian}

\section{Uji Validitas}

Hasil dari Faktor Analisis Rotate Component Matrix terlihat bahwa seluruh variabel yang meliputi harga, kualitas pelayanan, kualitas produk, kepuasan pelanggan dan minat beli ulang memiliki loading faktor signifikan yang besar yaitu diatas 0,50 . Untuk lebih jelasnya lihatlah tabel di bawah ini.

Tabel 1. Hasil Faktor Analisis Rotate Component Matrix

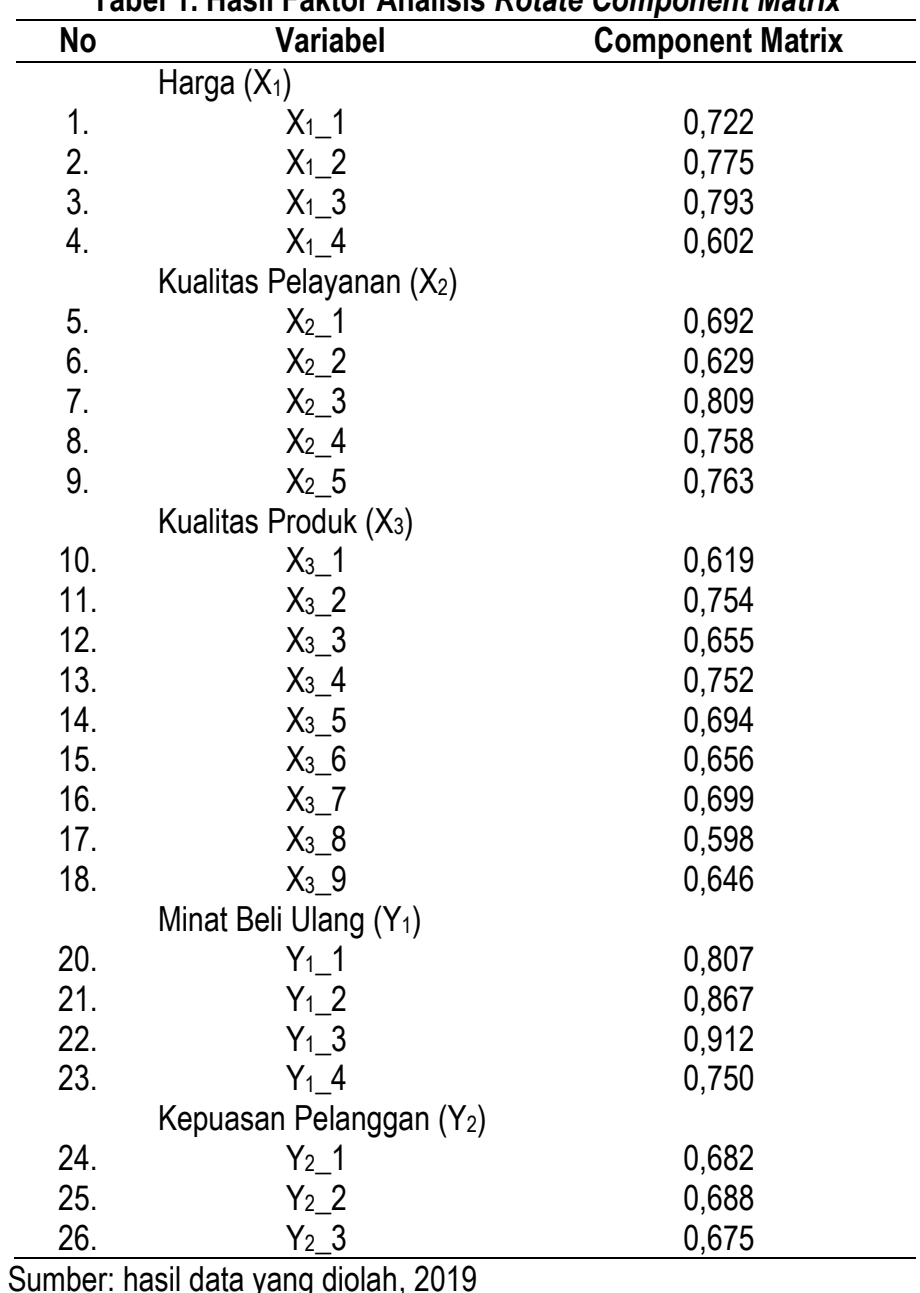

Hasil dari Tabel diatas menunjukkan bahwa masing-masing variabel memiliki factor loading signifikan yang besar yaitu diatas 0,50 yang artinya bahwa kelima variabel dinyatakan valid.

\section{Uji Reliabilitas}

Hasil pengolahan data untuk menghitung reliabilitas digunakan composite (construct) reliability dengan cutt off value minimal 0,70 (Solimun, 2002:71). Lebih jelasnya, lihatlah tabel dibawah ini.

Tabel 2. Uji Reliabilitas

\begin{tabular}{ccccccc}
\hline No. & Variabel & Indikator & Loading & $\boldsymbol{\Lambda}^{\mathbf{2}}$ & $\mathbf{1 - \boldsymbol { \Lambda } ^ { \mathbf { 2 } }}$ & $\mathbf{C R}$ \\
\hline 1. & Harga $\left(\mathrm{X}_{1}\right)$ & $\mathrm{X}_{1} 1$ & 0,722 & 0,521 & 0,479 & \\
& & $\mathrm{X}_{1}$ 2 & 0,775 & 0,600 & 0,400 & \\
& & $\mathrm{X}_{1}$ 3 & 0,793 & 0,629 & 0,371 & $\mathbf{0 , 7 8 9}$ \\
& & $\mathrm{X}_{1}$ 4 & 0,602 & 0,363 & 0,637 & \\
& & & $\mathbf{2 , 6 5 3}$ & & $\mathbf{1 , 8 8 7}$ & \\
\hline
\end{tabular}




\begin{tabular}{|c|c|c|c|c|c|c|}
\hline No. & Variabel & Indikator & Loading & $\lambda^{2}$ & $1-\lambda^{2}$ & CR \\
\hline \multirow[t]{6}{*}{2.} & Kualitas & $X_{2 \_} 1$ & 0,692 & 0,478 & 0,522 & \multirow{6}{*}{0,852} \\
\hline & Pelayanan $\left(\mathrm{X}_{2}\right)$ & $X_{2} \_2$ & 0,629 & 0,396 & 0,604 & \\
\hline & & $X_{2}{ }_{3}$ & 0,809 & 0,655 & 0,345 & \\
\hline & & $X_{2}{ }_{4} 4$ & 0,758 & 0,574 & 0,426 & \\
\hline & & $X_{2}{ }_{5}$ & 0,763 & 0,582 & 0,418 & \\
\hline & & & 3,651 & & 2,315 & \\
\hline \multirow[t]{10}{*}{3.} & Kualitas Produk & $X_{3} 1$ & 0,619 & 0,383 & 0,617 & \multirow{10}{*}{0,883} \\
\hline & $\left(X_{3}\right)$ & $X_{3 \_} 2$ & 0,754 & 0,568 & 0,432 & \\
\hline & & $X_{3} 3$ & 0,655 & 0,429 & 0,571 & \\
\hline & & $X_{3} 4$ & 0,752 & 0,566 & 0,434 & \\
\hline & & $X_{3}{ }_{5}$ & 0,694 & 0,482 & 0,518 & \\
\hline & & $x_{3 \_} 6$ & 0,656 & 0,431 & 0,569 & \\
\hline & & $X_{3 \_} 7$ & 0,699 & 0,489 & 0,511 & \\
\hline & & $X_{3 \_} 8$ & 0,598 & 0,357 & 0,643 & \\
\hline & & $X_{3 \_} 9$ & 0,646 & 0,417 & 0,583 & \\
\hline & & & 6,073 & & 4,878 & \\
\hline \multirow[t]{5}{*}{4.} & Minat Beli Ulang & $Y_{1}{ }_{1}$ & 0,807 & 0,652 & 0,348 & \multirow{5}{*}{0,902} \\
\hline & $\left(Y_{1}\right)$ & $Y_{1} \_2$ & 0,867 & 0,751 & 0,249 & \\
\hline & & $Y_{1} \_3$ & 0,912 & 0,832 & 0,168 & \\
\hline & & $Y_{1} \_4$ & 0,750 & 0,562 & 0,438 & \\
\hline & & & 3,336 & & 1,203 & \\
\hline \multirow[t]{4}{*}{5.} & Kepuasan & $Y_{2}{ }_{1}$ & 0,682 & 0,465 & 0,535 & \multirow{4}{*}{0,723} \\
\hline & Pelanggan ( $\left.\mathrm{Y}_{2}\right)$ & $Y_{2} \_2$ & 0,688 & 0,473 & 0,527 & \\
\hline & & Y2_3 & 0,675 & 0,456 & 0,544 & \\
\hline & & & 2,045 & & 1,606 & \\
\hline
\end{tabular}

Hasil tabel diatas menunjukkan bahwa composite (construct) reliability dengan cutt off value diatas 0,70 dan dinyatakan reliabel sehingga keseluruhan variabel mermiliki kemampuan konsistensi yang tinggi.

\section{Uji Normalitas Data}

Uji normalitas data dengan normalitas univariate dan multivariate yaitu menganalisis tingkat normalitas data yang digunakan dalam penelitian ini. Univariate dilihat dari nilai C.R pada Skewness nilai multivariate berkisar \pm 2.58 . Hasil selengkapnya uji normalitas dapat dilihat dari tabel berikut.

Tabel 3. Uji Normalitas Data

\begin{tabular}{|c|c|c|c|c|c|c|}
\hline Variable & $\min$ & $\max$ & skew & c.r. & kurtosis & c.r. \\
\hline Y23 & 1,000 & 5,000 & $-0,939$ & $-2,287$ & 0,770 & 1,757 \\
Y22 & 2,000 & 5,000 & $-0,740$ & $-1,379$ & 0,610 & 1,391 \\
Y21 & 1,000 & 5,000 & $-1,649$ & $-1,528$ & 3,442 & 1,855 \\
Y14 & 1,000 & 5,000 & $-0,701$ & $-2,200$ & 0,274 & 0,625 \\
Y13 & 1,000 & 5,000 & $-0,550$ & $-1,511$ & $-0,528$ & $-1,205$ \\
Y12 & 1,000 & 5,000 & $-0,641$ & $-1,925$ & 0,087 & 0,198 \\
Y11 & 1,000 & 5,000 & $-0,373$ & $-1,704$ & $-0,212$ & $-0,483$ \\
X31 & 1,000 & 5,000 & $-0,130$ & $-.0,594$ & $-1,056$ & $-2,411$ \\
X32 & 1,000 & 5,000 & $-0,435$ & $-1,985$ & $-0,691$ & $-1,577$ \\
X33 & 1,000 & 5,000 & $-0,763$ & $-1,482$ & 0,393 & 0,897 \\
X34 & 1,000 & 5,000 & $-0,812$ & $-1,708$ & 0,044 & 0,100 \\
X35 & 1,000 & 5,000 & 0,046 & 0,209 & $-0,944$ & $-2,154$ \\
X36 & 1,000 & 5,000 & $-0,578$ & $-1,640$ & $-0,521$ & $-1,190$ \\
X37 & 2,000 & 5,000 & $-0,497$ & $-2,270$ & $-0,497$ & $-1,134$ \\
X38 & 1,000 & 5,000 & 0,222 & 1,012 & $-0,860$ & $-1,964$ \\
X39 & 1,000 & 5,000 & $-0,586$ & $-0,676$ & $-0,325$ & $-0,741$ \\
X21 & 1,000 & 5,000 & $-0,497$ & $-2,267$ & $-0,951$ & $-2,171$ \\
\hline
\end{tabular}




\begin{tabular}{|c|c|c|c|c|c|c|}
\hline Variable & $\min$ & $\max$ & skew & c.r. & kurtosis & c.r. \\
\hline X22 & 1,000 & 5,000 & $-1,214$ & $-1,540$ & 1,575 & 1,594 \\
X23 & 1,000 & 5,000 & $-0,390$ & $-1,782$ & $-0,601$ & $-1,372$ \\
X24 & 1,000 & 5,000 & $-0,151$ & $-0,688$ & $-1,249$ & $-0,850$ \\
X25 & 1,000 & 5,000 & $-0,235$ & $-1,071$ & $-0,951$ & $-2,169$ \\
X14 & 2,000 & 5,000 & $-0,355$ & $-1,622$ & $-0,737$ & $-1,682$ \\
X13 & 1,000 & 5,000 & $-0,959$ & $-1,379$ & 0,812 & 1,854 \\
X12 & 1,000 & 5,000 & $-0,865$ & $-0,947$ & 0,772 & 1,762 \\
X11 & 1,000 & 5,000 & $-1,030$ & $-1,702$ & 1,049 & 1,394 \\
Multivariate & & & & & 24,324 & 2,308 \\
\hline
\end{tabular}

Sumber: hasil data yang diolah, 2019

Terlihat hasil pengujian normalitas data dalam penelitian ini, secara univariate untuk nilai-nilai dalam C.R skewness, semua item pada kisaran \pm 2.58 . dengan demikian secara univariate data terdistribusi secara normal, sedangkan nilai multivariate yang didapat adalah angka 2,308 dan masih pada kisaran \pm 2.58 sehingga bisa diartikan data terdistribusi normal.

\section{Analisis Structural Equation Modelling (SEM)}

Pengujian dengan menggunakan metode SEM dilakukan dengan pengujian terhadap kesesuaian model melalui telaah terhadap berbagai kriteria goodness of fit. Kerangka pemikiran teoritis yang tertera bahwa variabel harga, kualitas pelayanan dan kualitas produk mempengaruhi kepuasan pelanggan dan minat beli ulang pelanggan sebelum dilakukan pengolahan data menggunakan AMOS. Asumsi nilai goodness of fit dari model penelitian ini dapat dilihat dari path diagram pada tabel di bawah ini.

Tabel 4. Hasil Uji Goodness Of Fit Model

\begin{tabular}{clccc}
\hline No. & Goodness of fit index & Cut-of value & Hasil Analisis & Evaluasi Model \\
\hline 1. & Chi-square $X^{2}$ & $X^{2} \leq 258,8365$ & 266,677 & Marginal \\
2. & Significant probability & $\geq 0,05$ & 0,163 & Baik \\
3. & RMSEA & $\leq 0,08$ & 0,027 & Baik \\
4. & GFI & $\geq 0,90$ & 0,860 & Marginal \\
5. & AGFI & $\geq 0,90$ & 0,814 & Marginal \\
6. & CMIN/DF & $\leq 2,0$ & 1,088 & Baik \\
7. & TLI & $\geq 0,95$ & 0,984 & Baik \\
8. & CFI & $\geq 0,95$ & 0,987 & Baik \\
\hline
\end{tabular}

Sumber: hasil data yang diolah, 2019

Dari tabel diatas menunjukkan bahwa, $X^{2}$ Chi-square statistik, dimana model dipandang baik atau memuaskan jika nilai chi-squarenya rendah. Semakin kecil nilai $X^{2}$ semakin baik model itu dan diterima. Pada penelitian ini cut of value dari chi-square adalah 258,8365 dengan hasil analisis yang lebih besar yaitu 266,677 ditambah dengan hasil significant probability sebesar 0,163 dengan cut of value $\geq 0,05$ menunjukkan bahwa model penelitian ini memiliki tingkat kesesuaian yang marginal.

The Root Mean Square Error of Approximation (RMSEA) adalah indeks yang digunakan untuk mengkompensasi nilai Chi-Square dalam sampel yang besar. Nilai yang direkomendasikan $\leq 0,08$ dan nilai RMSEA model adalah sebesar 0,027 menunjukkan tingkat kesesuaian yang baik.

Goodness of Fit Index (GFI) menunjukkan tingkat kesesuaian model secara keseluruhan yang dihitung dari residual kuadrat dari model yang diprediksi dibandingkan data yang sebenarnya. Nilai yang mendekati 1 mengisyaratkan model yang diuji memiliki kesesuaian yang baik. Tingkat penerimaan yang direkomendasikan $\geq$ 0,90 dapat disimpulkan bahwa model penelitian ini memiliki tingkat kesesuaian yang marginal dengan nilai mendekati kriteria sebesar 0,860 . 
Nilai marginal adalah kondisi kesesuaian model pengukuran dibawah kriteria ukuran absolute fit maupun incremental fit, namun masih dapat diteruskan pada analisis lebih lanjut karena dekat dengan kriteria good fit (Seguro, 2008). Adjusted Goodness of Fit Index (AGFI) adalah GFI yang disesuaikan dengan rasio antara degree of fredom dari model yang diusulkan dan degree of fredom dari null model. Tingkat penerimaan yang direkomendasikan $\geq 0,90$. Nilai AGFI dalam model ini 0,814 menunjukkan bahwa model memiliki kesesuaian yang marginal.

Normed Chi-square (CMIN/DF) adalah ukuran yang diperoleh dari nilai Chi-Square dibagi dengan degree of freedom. Indeks ini merupakan indeks kesesuaian parsimonius model dengan jumlah koefisien-koefisien estimasi yang diharapkan untuk mencapai tingkat kesesuaian. Nilai CMIN/DF pada model ini adalah 1,088 menunjukkan bahwa model penelitian ini baik melihat cut of value-nya $\leq 2,0$. Tucker Lewis Index (TLI) adalah indeks kesesuaian incremental yang membandingkan model yang diuji dengan baseline model. TLI merupakan indeks kesesuain model yang kurang dipengaruhi oleh ukuran sampel. Nilai yang direkomendasikan $\geq 0,95$. Disimpulkan bahwa model yang diajukan memiliki tingkat kesesuaian yang baik dengan nilai TLI sebesar 0,984.

Comparative Fit Index (CFI) adalah indeks kesesuaian incremental yang membandingkan model yang diuji dengan null model. Besaran indeks ini dalam rentang 0 sampai 1 dan nilai yang mendekati 1 mengidentifikasikan model memiliki tingkat kesesuaian yang baik. Indeks ini sangat dianjurkan untuk dipakai karena relatif tidak sensitif dengan besarnya sampel tidak dipengaruhi oleh kerumitan model. Memperhatikan nilai yang direkomendasikan yaitu $\geq 0,95$, maka nilai CFI sebesar 0,987 menunjukkan bahwa model ini memiliki kesesuaian yang baik. Pengukuran keseluruhan dari Goodness of Fit tersebut diatas mengindentifikasikan bahwa model yang diajukan dalam penelitian ini dapat diterima.

\section{Uji Hipotesis}

Pada uji hipotesis ini, dapat dilihat dari signifikan apabila nilai $C R>1,96$ dan nilai $P<0,05$. Analisis ini dilihat dari besaran regression weight model yang dapat dilihat dari tabel berikut.

Tabel 5. Regression Weight

\begin{tabular}{|c|c|c|c|c|c|c|c|}
\hline No. & $\begin{array}{c}\text { Variabel } \\
\text { Dipengaruhi }\end{array}$ & & $\begin{array}{c}\text { Variabel } \\
\text { Mempengaruhi }\end{array}$ & Estimate & S.E. & C.R. & $P$ \\
\hline 1. & Minat beli ulang & $\longleftarrow$ & Harga & 0,203 & 0,100 & 2,033 & 0,042 \\
\hline 2. & Minat beli ulang & $\longleftarrow$ & Kualitas pelayanan & 0,360 & 0,116 & 3,106 & 0,002 \\
\hline 3. & Minat beli ulang & & Kualitas produk & 0,293 & 0,143 & 2,044 & 0,041 \\
\hline 4. & $\begin{array}{l}\text { Kepuasan } \\
\text { pelanggan }\end{array}$ & & Harga & 0,168 & 0,083 & 2,031 & 0,042 \\
\hline 5. & $\begin{array}{l}\text { Kepuasan } \\
\text { pelanggan }\end{array}$ & & Kualitas pelayanan & 0,216 & 0,104 & 2,075 & 0,038 \\
\hline 6. & $\begin{array}{l}\text { Kepuasan } \\
\text { pelanggan }\end{array}$ & & Kualitas produk & 0,239 & 0,116 & 2,069 & 0,039 \\
\hline 7. & $\begin{array}{l}\text { Kepuasan } \\
\text { pelanggan }\end{array}$ & 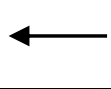 & Minat beli ulang & 0,257 & 0,101 & 2,548 & 0,011 \\
\hline
\end{tabular}

Sumber: hasil data yang diolah, 2019

Hasil pengujian pertama menyatakan bahwa antara Harga, Kualitas Pelayanan dan Kualitas Produk dengan Minat Beli Ulang terdapat nilai CR lebih besar dari 1,96 yaitu 2,033 $\left(X_{1}\right), 3,106\left(X_{2}\right)$ dan 2,044 (X3) dan Probabilitas kurang dari 0,05 yaitu $0,042\left(X_{1}\right), 0,002\left(X_{2}\right)$ dan $0,041\left(X_{3}\right)$ maka terdapat pengaruh positif yang signifikan antara Harga, Kualitas Pelayanan dan Kualitas Produk dengan Minat Beli Ulang.

Hasil pengujian kedua menyatakan bahwa antara Harga, Kualitas Pelayanan dan Kualitas Produk dengan Kepuasan Pelanggan terdapat nilai CR lebih besar dari 1,96 yaitu 2,031 $\left(X_{1}\right), 2,075\left(X_{2}\right)$ dan 2,069 $\left(X_{3}\right)$ dan Probabilitas kurang dari 0,05 yaitu $0,042\left(X_{1}\right), 0,038\left(X_{2}\right)$ dan $0,039\left(X_{3}\right)$ maka terdapat pengaruh positif yang signifikan antara Harga, Kualitas Pelayanan dan Kualitas Produk dengan Kepuasan Pelanggan. 
Hasil pengujian ketiga menyatakan bahwa antara Minat Beli Ulang dengan Kepuasan Pelanggan terdapat nilai CR lebih besar dari 1,96 yaitu 2,548 dan Probabilitas kurang dari 0,05 yaitu 0,011 maka terdapat pengaruh positif yang signifikan antara Minat Beli Ulang dengan Kepuasan Pelanggan.

\section{Pembahasan}

\section{Pengaruh Harga Terhadap Minat Pembelian Ulang Online Shopping}

Hasil penelitian menunjukkan bahwa harga berpengaruh signifikan terhadap minat pembelian ulang dengan arah hubungan positif. Remaja di Situbondo mengaku bahwa harga barang-barang yang ditawarkan oleh online shop sangat terjangkau sehingga melakukan pembelian ulang yang akan mengakibatkan mereka akan merekomendasikan online shop langganannya kepada teman atau orang lain. Selain itu faktor lain dari harga yaitu kesesuaian harga dengan kualitas produk, manfaat yang diterima dan kesesuaian daya saing harga mempengaruhi dalam pembelian ulang. Hasil penelitian ini mendukung penelitian sebelumnya yang dilakukan oleh Lestari, dkk. (2013), serta Faradiba dan Astuti (2013) yang menyatakan bahwa harga berpengaruh signifikan terhadap minat pembelian ulang. Hal ini menunjukkan bahwa semakin cocok harga yang dirasakan oleh Remaja di Situbondo maka minat pembelian ulang semakin tinggi dikarenakan pelanggan online shop membandingkan harga toko online satu dengan yang lainnya sehingga berdampak pada minat pembelian ulang.

\section{Pengaruh Kualitas Pelayanan Terhadap Minat Pembelian Ulang Online Shopping}

Hasil penelitian menunjukkan bahwa kualitas pelayanan berpengaruh signifikan terhadap minat pembelian ulang dengan arah hubungan positif. Remaja di Situbondo mengaku bahwa dalam berbelanja online yang menjadi pertimbangan pertama kali dalam memutuskan pembelian produk adalah kualitas pelayanan, jika online shop melayani dengan baik dan memberikan informasi yang cepat, maka akan meningkatkan pembelian ulang di masa yang akan datang serta akan merekomendasikan kepada orang lain. Hal ini disebabkan karena kenyamanan dalam berkomunikasi dengan online shop mampu membuat seseorang merasa senang untuk berbelanja kembali di online shop tersebut. Hasil penelitian ini mendukung penelitian sebelumnya yang dilakukan oleh Bayhaqi (2006) dan Kim, et al. (2012) serta Faradiba dan Astuti (2013) yang menyatakan bahwa kualitas pelayanan berpengaruh signifikan terhadap minat pembelian ulang. Hal ini menunjukkan bahwa semakin meningkatnya kualitas pelayanan maka minat pembelian ulang semakin tinggi.

\section{Pengaruh Kualitas Produk Terhadap Minat Pembelian Ulang Online Shopping}

Hasil penelitian menunjukkan bahwa kualitas produk berpengaruh signifikan terhadap minat pembelian ulang dengan arah hubungan positif. Remaja di Situbondo mengaku b produk yang diterima akurat atau sesuai dengan yang ditampilkan pada gambar atau foto sehingga mengakibatkan minat pembelian ulang semakin bertambah dan para remaja akan merekomendasikan kepada orang lain atau memberikan feedback yang bagus kepada salah satu online shop yang tingkat kemampuan produknya baik dan sesuai dengan produk yang ditawarkan. Hasil penelitian ini mendukung penelitian sebelumnya yang dilakukan oleh Lin, et al. (2011) dan Faradiba dan Astuti (2013) dan yang menyatakan bahwa kualitas produk berpengaruh signifikan terhadap minat pembelian ulang. Hal ini dikarenakan pada saat pelanggan melakukan online shopping cenderung melihat kualitas produk yang ditawarkan oleh online shop, hal ini akan berdampak pada minat pembelian ulang.

\section{Pengaruh Harga Terhadap Kepuasan Pelanggan Online Shopping}

Hasil penelitian menunjukkan bahwa harga berpengaruh signifikan terhadap kepuasan pelanggan dengan arah hubungan positif. Remaja di Situbondo sangat sensitif terhadap harga dan mengutamakan kesesuaian harga dengan kualitas produk yang didapatkannya setelah berbelanja. Beberapa online shop berlomba-lomba menjual produknya dengan harga yang "murah", hal ini menimbulkan daya saing harga yang bertujuan agar konsumen tertarik untuk membelinya sehingga mengakibatkan kepuasan pelanggan. Hasil penelitian ini 
mendukung penelitian sebelumnya yang dilakukan oleh Prasetio (2012) dan Damanhuri, dkk. (2013) yang menyatakan bahwa harga berpengaruh signifikan terhadap minat pembelian ulang. Hal ini menunjukkan bahwa kesesuaian harga dengan kualitas produknya akan meningkatkan kepuasan pelanggan, dan sebaliknya jika harga tidak sesuai dengan kualitas produk maka kepuasan pelanggan akan menurun.

\section{Pengaruh Kualitas Pelayanan Terhadap Kepuasan Pelanggan Online Shopping}

Hasil penelitian menunjukkan bahwa kualitas pelayanan berpengaruh signifikan terhadap kepuasan pelanggan dengan arah hubungan positif. Remaja di Situbondo mengaku bahwa dalam berbelanja online shop yang pertama kali dilakukan adalah berkomunikasi dengan pemilik online shop tersebut, sehingga mereka dapat menilai bahwa pemilik online shop mampu memberikan informasi tentang produk yang diinginkan. Hal ini menunjukkan bahwa semakin meningkatnya kualitas pelayanan maka kepuasan pelanggan semakin tinggi. Hasil penelitian ini mendukung penelitian sebelumnya yang dilakukan oleh Lin, et al. (2011) serta Sukmawati dan Massie (2015) yang menyatakan bahwa kualitas pelayanan berpengaruh signifikan terhadap kepuasan pelanggan. Hal ini dikarenakan pelanggan online shop lebih mengutamakan kualitas pelayanan dibandingkan faktor-faktor lain seperti harga dan kualitas produk sehingga berdampak pada kepuasan pelanggan.

\section{Pengaruh Kualitas Produk Terhadap Kepuasan Pelanggan Online Shopping}

Hasil penelitian menunjukkan bahwa kualitas produk berpengaruh signifikan terhadap kepuasan pelanggan dengan arah hubungan positif. Remaja di Situbondo mengaku memprioritaskan ketersediaan produk dengan berbagai macam model atau ukuran sesuai kebutuhannya. Hal ini menunjukkan bahwa semakin meningkatnya kualitas produk maka kepuasan pelanggan semakin tinggi sehingga pelanggan online shop memilih toko online sesuai rekomendasi dari orang lain yang sudah berpengalaman membeli produknya sehingga berdampak pada kepuasan pelanggan. Hasil penelitian ini mendukung penelitian sebelumnya yang dilakukan oleh Lin, et al. (2011) dan Damanhuri, dkk. (2013) yang menyatakan bahwa kualitas produk berpengaruh positif dan signifikan terhadap kepuasan pelanggan online.

\section{Pengaruh Minat Pembelian Ulang Terhadap Kepuasan Pelanggan Online Shopping}

Hasil penelitian menunjukkan bahwa minat pembelian berpengaruh signifikan terhadap kepuasan pelanggan dengan arah hubungan positif. Remaja di Situbondo yang berlangganan online shopping berjenis kelamin wanita, mereka cenderung suka membicarakan tentang hal fashion, sehingga dari hasil perbincangan tersebut mendapatkan rekomendasi dari teman-temannya yang sudah berpengalaman membeli produk online shop. Hal ini dikarenakan pelanggan online shop memiliki loyalitas kepada salah satu online shop yang dipercayainya sehingga berdampak pada minat pembelian ulang dan kepuasan pelanggan. Hasil penelitian ini mendukung penelitian sebelumnya yang dilakukan oleh Hsu, et al. (2014) yang menyatakan bahwa minat pembelian ulang berpengaruh signifikan terhadap kepuasan pelanggan. Hal ini menunjukkan bahwa semakin meningkatnya minat pembelian ulang maka kepuasan pelanggan semakin tinggi.

\section{Kesimpulan}

Hasil penelitian menunjukan harga, kualitas pelayanan dan kualitas produk berpengaruh signifikan terhadap minat pembelian ulang dan harga, serta minat pembelian ulang berpengaruh signifikan terhadap kepuasan pelanggan online shopping. Hasil penelitian memiliki implikasi yaitu dapat menjadi bahan masukan bagi pemilik online shop dalam menjual produknya agar lebih berinovasi untuk meningkatkan minat pembelian dan kepuasan pelanggan dalam pembelian produk online tersebut. Bisnis online semakin terbuka untuk menjalankan peluang bagi pelaku bisnis di Indonesia karena terjadi pemutusan rantai perantara yang substansial dari pedagang grosir ke pengecer yang disebabkan oleh perdagangan secara elektronik. Bisnis online atau usaha online shop juga dapat lebih memperhatikan harga, kualitas pelayanan dan kualitas produk yang dimiliki agar dapat meningkatkan minat pembelian dan kepuasan pelanggan. Keterbatasan penelitian ini adalah meneliti remaja di Situbondo yang hanya diwakilkan oleh 125 remaja dari 17 kecamatan yang ada di Situbondo. Penelitian selanjutnya dapat 
memperluas sampel penelitian pada semua kalangan masyarakat yang tidak hanya terbatas untuk para remaja. Terakhir, Peneliti mengucapkan terimakasih kepada Kementrian Riset, Teknologi, dan Pendidikan Tinggi atas pendanaan penelitian ini.

\section{Daftar Pustaka}

Bayhaqi, Yuzza. 2006. "Analisis Pengaruh Kualitas Layanan, dan Keunggulan Produk Terhadap Kepuasan Pelanggan dan Dampaknya Pada Minat Membeli Ulang (Studi Kasus: Pada Auto Bridal Semarang)." Tidak Diterbitkan. Tesis. Semarang: program Pascasarjana Universitas Diponegoro.

Damanhuri., Firdaus, M., dan Dahliani, Y. 2013. Analisis Pengaruh Kualitas Produk, Kualitas Pelayanan, Dan Harga Terhadap Kepuasan Pelanggan (Studi Kasus Pada Home Industri Kaca Grafir Di Desa Grujugan Kidul Kecamatan Grujugan Bondowoso). Jurnal Relasi. Vol. 17 (1): 60-72.

Faradiba dan Astuti, S. R. T. 2013. Analisis Pengaruh Kualitas Produk, Harga, Lokasi Dan Kualitas Pelayanan Terhadap Minat Beli Ulang Konsumen (Studi pada Warung Makan "Bebek Gendut" Semarang) Diponegoro. Journal Of Management. Vol. 2 (3): 1-11.

Hsu, Meng-Hsiang,. Chang, Chun-Ming,. Chu, Kuo-Kuang and Lee, Yi-Jung. 2014. Determinant of repurchase intention in online group-buying: The perspectives of delone \& McLean success model and trust. Computer in Human Behaviour. Vol. 26 (6): 234-245.

Hurlock. 2003. Psikologi Perkembangan. Jakarta: Erlangga.

Kim, Changsu,. Galliers, Robert D., Ryood, Joo-Han,. Shinc, Namchul and Kime, Jongheon. 2012. Factors Influencing Internet Shopping Value and Customer Repurchase Intention. Electronic Commerce Research and Applications. Vol. 11 (4): 374-387.

Kotler, Philip. 2007. Manajemen Pemasaran. Jakarta: Penerbit Airlangga.

Lestari, Putri Dewi., Firdaus, M., dan Hidayah, T. 2013. Analisis Pengaruh Layanan, Harga, Dan Kualitas Produk Pakaian Wanita Yang Dijual Secara Online Melalui Group Blackbery Messenger Terhadap Minat Beli Konsumen (Studi Kasus Mahasiswi Stie Mandala Jember). Jurnal Relasi. Vol. 17 (1): 89-98.

Lin, chun-chun., Wu, Hsueh-Ying., and Chang, Yong-Fu. 2011. The critical factors impact on online customer satisfaction. Procedia Computer Science. Vol. 3 (1): 276-281.

Meskaran, Fatemeh., Ismail, Zuraini., and Shanmugam, Bharani. 2013. Online Purchase Intention: Effects of Trust and Security Perception. Australian Journal of Basic and Applied Sciences. Vol. 7 (6): 307-315.

Nurtjahjanti, H. 2012. Hubungan Antara Persepsi terhadap Harga dan Kualitas Produk Dengan Minat Membeli Produk Fashion Online Shopping di Facebook Pada Mahasiswa Politeknik X Semarang. Jurnal Psikologi. Vol. 11 (2): 1-8.

Praja, D. D. dan Damayantie, A. 2010. Potret Gaya Hidup Hedonisme di Kalangan Mahasiswa. Jurnal Sociologie Universitas Lampung. Vol. 1 (3): 184 - 193.

Prasetio, Ari. 2012. Pengaruh Kualitas Pelayanan Dan Harga Terhadap Kepuasan Pelanggan. Management Analysis Journal. Vol. 1. (2): 1-8.

Sarwono, S.W. 2006. Psikologi Remaja. Jakarta: PT. Raja Grafindo Persada

Setiowati, A, K, W., dan By, Jasly. 2012. Sikap Online Shopping Dan Niat Pencarian Informasi Terhadap Niat dan Perilaku Belanja. Jurnal Manajemen Bisnis. Vol. 2. (1): 3-8.

Solimun. 2002. Multivariate Analysis Structural Equation Modelling (SEM) Lisrel danAmos. Fakultas MIPA: Universitas Brawijaya.

Sudaryanto. 2011. The Need For ICT Education For Managers Or Agri-Businessmen For Increasing Farm Income: Study Of Factor Influences On Computer Adoption In East Java Farm Agribusiness. International 
Journal Of Education And Development Using Information And Communication Technology (IJEDICT). Vol. 7 (1): 56-67.

Sukmawati, Ida., dan Massie, J. D. D. 2015. Pengaruh Kualitas Pelayanan Dimediasi Kepuasan Pelanggan Dan Kepercayaan Pelanggan Terhadap Loyalitas Pelanggan Pada PT Air Manado. Jurnal EMBA. Vol. 3 (3): 729-742. 